\title{
Section Discretization for Multi-Axial Spring Model
}

\author{
Gao Jinhe ${ }^{1,2, a}$, Huang Yanbin ${ }^{2, b}$, Zhang Shoulong, ${ }^{2, c}$, \\ Zhang Yinghui2,d and Geng Jinlei2,e,Xiang Tao2 \\ ${ }^{1}$ School of Civil Engineering, Tongji University, China \\ ${ }^{2}$ School of Architecture and Civil Engineering, East China Institute of \\ Technology, China \\ ajinhegao@aliyun.com, ${ }^{b} 1129250689 @ q q . c o m,{ }^{c} 937910622 @ q q . c o m,{ }^{d} 2$ \\ 84127705@qq.com, ${ }^{e}$ gengjinlei1995@qq.com
}

\begin{abstract}
.
Discretization of the basic-shape areas is described in the paper. Using Multi-axial spring model (called MS model) or fiber model for structural member idealization, the critical sections of the member are discretized in to a number of small elements (represented by springs or fibers) according to the section properties and materials (steel and/or concrete) properties.

Keywords: Section Discretization; Multi-axial sprinf model; RC and SRC section

Introduction

\section{RC and SRC section}

Some basic-share areas, such as square, rectangle, triangle, circle and oval (rectangle with two semi-circles), are considered for the concrete area. Each basic-shape concrete area may be discriminated as cover concrete and core concrete. Usually the cover concrete is a thin or narrow strip and is divided and represented by one-row or one-column of concrete springs ${ }^{[1-3]}$. The core concrete area remains in similar shape of the whole basic-shape area. The steel bars in the RC and SRC section are treated. A steel spring/fiber represents a single steel bar and is placed in the steel-bar center point ${ }^{[4-5]}$.
\end{abstract}

\section{Steel section or the steel in SRC section}

Steel section or steel in SRC section is considered an assembly of thin steel 
plates. The basic-shape areas considered for the steel section or steel in SRC section are I-steel, L-steel, box-steel and pipe steel. As only thin steel plate is considered, a single row or column of steel springs is used to discretize and represent steel leg in the section.

\section{Discretization of square area}

As show in Fig. 1, the concrete in square area (side length A) may have different material properties for the cover concrete (thickness $\boldsymbol{t}_{\mathrm{c}}$ ) and the core concrete. The core concrete size is $a \times a$, where $a=A-2 t_{c}$. If no difference between cover and core concrete, then $\boldsymbol{a}=\boldsymbol{A}$.

Core concrete is divided in to $\boldsymbol{m}=\boldsymbol{k} \times \boldsymbol{k}$ equal area $a_{i}=a_{2} / \mathrm{m}$.

Cover concrete is discretized into $\boldsymbol{k}+\mathbf{4}$ concrete elements, matched divisions of the core area and plus the four-corners.

Area of the cover concrete element on side $a_{1}=t_{\mathrm{c}} \mathrm{a} / \mathrm{k}$

Area of the cover concrete element at corner $a_{0}=t_{\mathrm{c}} \times t_{\mathrm{c}}$

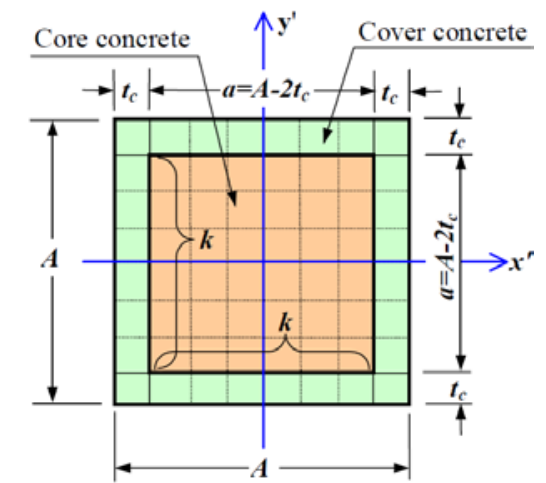

Fig. 1 Discretization of Square Concrete Area

\section{Discretization of circle area}

Considering the circular concrete area in two parts: the core concrete with radius $\boldsymbol{r}$, and the cover concrete with inner radius $\boldsymbol{r}$ and outer radius $\boldsymbol{R}$, as shown in Fig. 2. $\boldsymbol{R}-\boldsymbol{r}=$ the thickness of cover concrete ring. Core concrete is divided in to $\boldsymbol{m}$ rings.

The outer radius of the $j$-th ring is: 


$$
r_{j}=\frac{j}{m} \bullet r \quad(\mathrm{j}=1,2,3, \ldots, \mathrm{m})
$$

Each ring is divided again into small elements: 4 for the first ring (from the circle center), 12 for the second ring, 20 for the third ring, and so on. It reaches $(8 m-4)$ elements in the outer ring, and total $4 m^{2}$ divided elements. Thus it makes equal area for each element:

$$
\mathrm{a}_{i}=\frac{\pi r^{2}}{4 m^{2}}
$$

The center of the elements of $j$-th ring is on the circumference with radius of

$$
r_{j}^{\prime}=\frac{2}{3}\left\{r_{j-1}+\frac{r^{2}{ }_{j-1}+r_{j}}{r_{j-1}}\right\}
$$

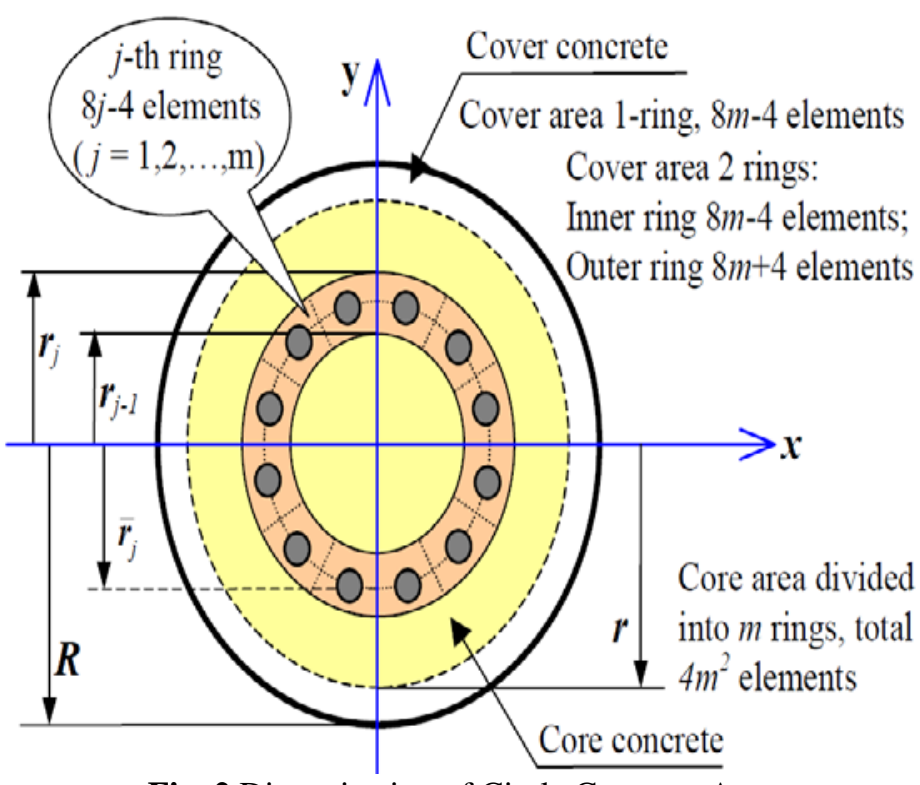

Fig. 2 Discretization of Circle Concrete Area

Cover concrete is made 1 ring or 2 rings according to the thickness. For 1-ring cover concrete it is divided into $8 \boldsymbol{m}$ - 4 elements, equal to the elements in the core concrete outer ring. The center of the divided cover concrete areas to the circle center is on the circumference of

$$
R^{\prime}=\frac{2}{3}\left\{r+\frac{R^{2}}{r+R}\right\}
$$




\section{Discretization of steel section}

For the steel section there are the following basic-shape areas: I-shape, $L$-shape, rectangle box and circular pipe, as show in Fig. 3 . In all cases it is required that the thickness of any steel plate in the section is much smaller than the dimension of the section area. That is because each steel plate or steel ring is discretized along length/width of the steel plate only, resulting in single steel spring/fiber in the thickness direction.

\section{Discretization of $I$-shape steel area:}

Estimated spring/fiber dimension is $d_{1}=\left(B+B+D-t_{f}-t_{f}\right) / n$, where $\boldsymbol{n}=$ the specified number of at least springs/fibers. The number of springs/fibers discretized for one flange plate is $n_{1}=B / d_{1}\left(n_{1} \geq 1\right)$, and for the web plate is $n_{2}$ $=\left(D-t_{f}-t_{f}\right) / d_{1}\left(n_{2} \geq 1\right)$.

\section{Discretization of $L$-shape steel area:}

Estimated spring/fiber dimension is $d_{1}=\left(B+D-t_{b}\right) / n$, where $\boldsymbol{n}=$ the specified number of at least springs/fibers. The $B$-leg plate is discretized in to $n_{1}=B / d_{1}\left(n_{1} \geq 1\right)$, and the $D$-leg plate $n_{2}=\left(D-t_{b}\right) / d_{1}\left(n_{2} \geq 1\right)$.

\section{Discretization of rectangle box steel area:}

Estimated dimension is $d_{1}=\left(2 B+2\left(D-2 t_{b}\right)\right) / n$, where $\boldsymbol{n}=$ the specified number of at least springs/fibers. The discretized number of springs/fibers for one $B$-leg plate is $n_{1}=B / d_{1}\left(n_{1} \geq 1\right)$, and for one $D$-leg plate is $n_{2}=\left(D-2 t_{b}\right)$ $/ d_{1}\left(n_{2} \geq 1\right)$.

\section{Discretization of circular steel pipe:}

The number of the spring/fibers, $\boldsymbol{n}$, must be integral multiple of number 4 . Equal spring/fiber area is made:

$$
\mathrm{a}_{i}=\frac{\pi(D-t) t}{n}
$$

The spring/fiber is placed at the central circumference with the radius: 


$$
r_{o}=\frac{1}{3}\left\{D-2 t+\frac{D^{2}}{2(D-t)}\right\}
$$

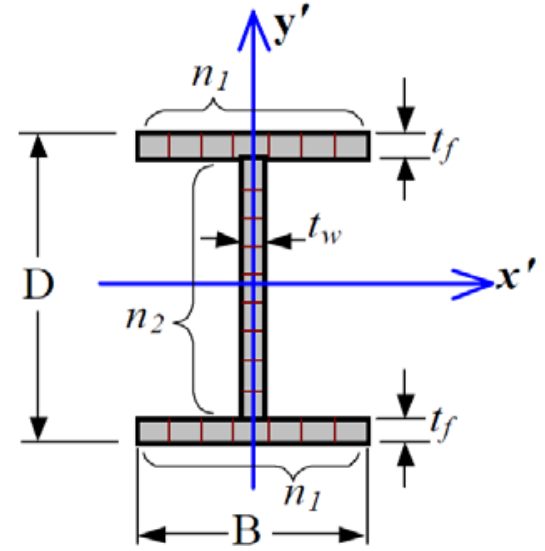

I-shape steel section

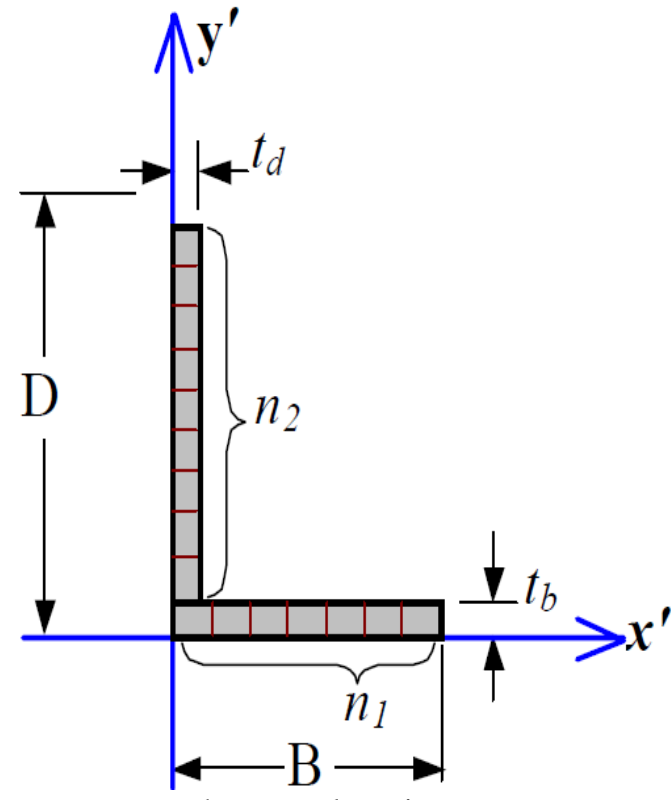

$L$-shape steel section 

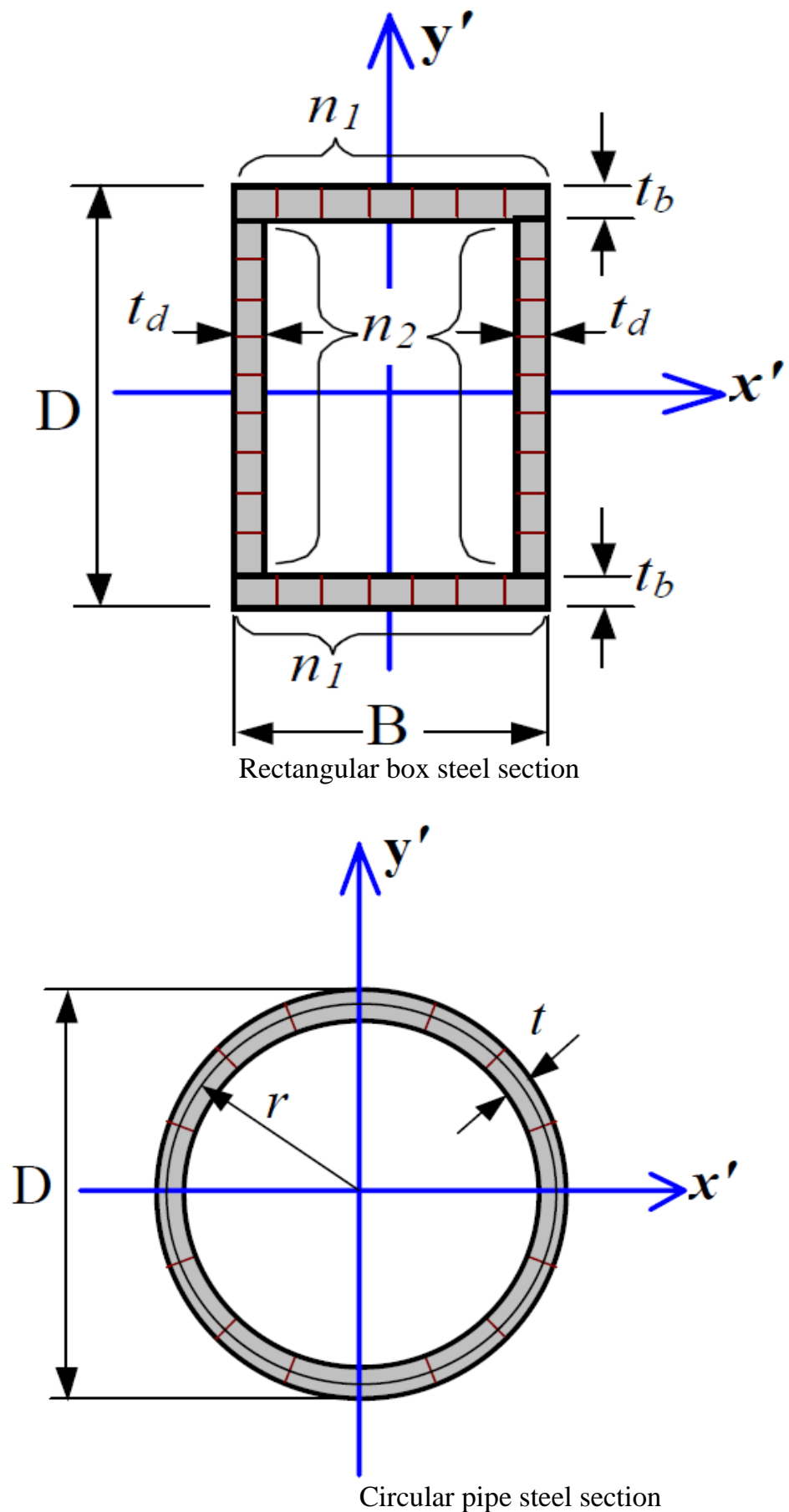

Fig. 3 Discretization of Steel Sections 


\section{Conclusion}

As to the complex structures, the theories of classical mechanics can hardly be used to analyze their structural responses in detail and accurately, so that optimal design should be carried out on the basis of finite element method. Making use of the structure elements and optimal of discretization proposed in this thesis, optimal design is carried out for a structure, with the objective function. The numerical results show that the method of this thesis is correct, effective and high efficiency.

\section{Acknowledgements}

This work was financially supported by the Jiangxi Science Foundation (20132BAB216007), scientific research fund of Jiangxi provincial education department (GJJ13440) and scientific research fund of East China Institute of Technology (DHBK201109).

\section{References}

[1] Kang-Ning Li and Shunsuke Otani, "Multi-Spring Model for 3-Dimensional Analysis of RC Members", Journal of Structural Engineering and Mechanics, Vol.1, No.1, 1993, pp. 17-30.

[2] Kang-Ning Li, "CANNY-C A Computer Program for 3D Nonlinear Dynamic Analysis of Building Structures," Research Report No.CE004, Department of Civil Engineering, National University of Singapore, November, 1993, 200p.

[3] Kang-Ning Li, "Analysis Model for 3D RC Columns Coupled with Shear Nonlinearity," Proceedings of the 9th Japan Earthquake Engineering Symposium, Vol.3, December 1994, pp. E-127-E-132.

[4] Kang-Ning Li and Tetsuo Kubo, "Reviewing the Multi-Spring Model and Fiber Model," The 10th Japan Earthquake Engineering Symposium, 1998, Volume 2, pp.2369-74.

[5] K. Li and X. Ye, "Equilibration of Element with Multi-Deformation 
Components for Nonlinear Structural Analysis", the 4th International Conference on Urban Earthquake Engineering, Tokyo Institute of Technology, Japan, March 2007. 